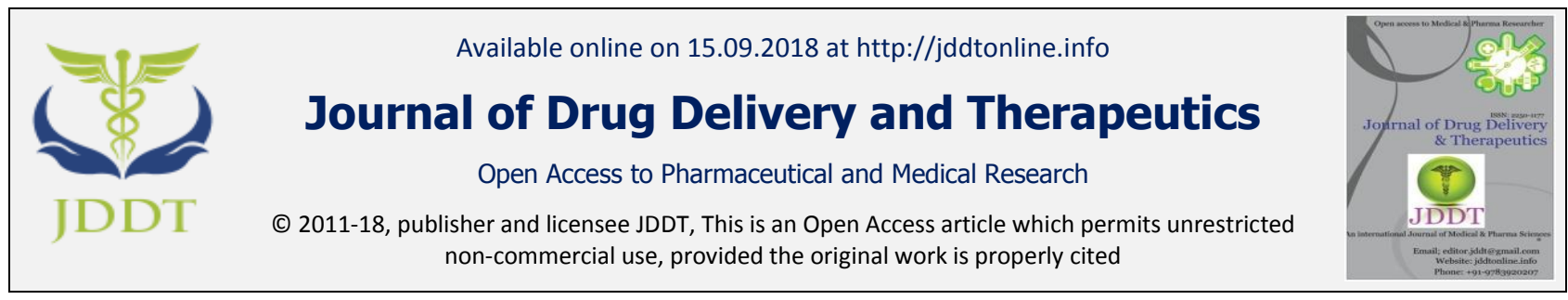

Open 6 Access

Research Article

\title{
FORMULATION DEVELOPMENT AND EVALUATION OF TRANSFEROSOMAL GEL
}

\author{
Neha Thakur*1, Prabhat Jain ${ }^{2}$, Vivek Jain ${ }^{1}$ \\ ${ }^{1}$ Nri Institute of Pharmacy, Bhopal, M.P., India \\ ${ }^{2}$ Scan Research Laboratories, Bhopal, M.P., India
}

\begin{abstract}
Transfersomes are particularly optimized, ultradeformable (ultraflexible) lipid supramolecular aggregates, which are able to penetrate the mammalian skin intact. Transfersome is a type of carrier system which is capable of transdermal delivery of low as well as high molecular weight drugs. Transfersomes penetrate through the pores of stratum corneum which are smaller than its size and get into the underlying viable skin in intact form. Acne vulgaris is a disease of the pilosebaceous follicle characterized by noninflammatory (open and closed comedones) and inflammatory lesions (papules, pustules, and nodules). In such situation transdermal drug delivery remains the most preferential mode of administration. But, stratum corneum forms the most formidable barrier for the penetration of drug through skin. To overcome the stratum corneum barrier, the use of lipid vesicles like transfersomes in delivery systems has involved increasing attention in recent years. The aim of the present study was to statistically optimize the vesicular formulations (Transfersomes) for enhanced skin delivery of a model drug Clindamycin Phosphate.
\end{abstract}

Keywords: Transfersomes, Acne vulgaris, Clindamycin Phosphate

Article Info: Received 20 June, 2018; Review Completed 29 July 2018; Accepted 05 Aug 2018; Available online 15 Sep 2018

\section{Cite this article as:}

Thakur T, Jain P, Jain V, Formulation development and evaluation of transferosomal gel, Journal of Drug Delivery and Therapeutics. 2018; 8(5):168-177 DOI: http://dx.doi.org/10.22270/jddt.v8i5.1826

*Address for Correspondence: Neha Thakur, Nri Institute of Pharmacy, Bhopal, M.P., India

\section{INTRODUCTION}

Acne vulgaris is a disease of the pilosebaceous follicle characterized by non-inflammatory (open and closed comedones) and inflammatory lesions (papules, pustules, and nodules). Its pathogenesis is multifactorial - the interplay of hormonal, bacterial, and immunological (inflammatory) factors results in the formation of acne lesions. ${ }^{2}$ Although acne is not a lifethreatening situation, it can have detrimental effects on the excellence of life of affected individuals. Fortunately, acne is readily approachable to the widerange of available medications, with the goals of therapy being to clear the lesions, prevent scarring, and limit any treatment-related side-effects. Clindamycin Phosphate is a antibiotic widely used for the treatment of acne. In oral dosage forms it produces pseudomonas colitis while in topical dosage forms it has side effects like irritation, skin rash, itching etc., it's topical bioavailability is also less. ${ }^{3,4}$ So, to overcome these limitations an attempt has been made to prepare transfersomes of Clindamycin Phosphate and optimize it for enhanced delivery through the skin. The aim of the present study was to statistically optimize the vesicular formulations (Transfersomes) for enhanced skin delivery of a model drug of Anti-acne drug Clindamycin Phosphate, which was effective candidate for the treatment of acne. ${ }^{1}$

\section{METHODS}

\section{Preformulation studies of clindamycin phosphate}

Preformulation studies are an important tool for determination of physical and chemical properties of the drug before incorporating it in formulation development programmed. ${ }^{5-9,19-21}$

Physical appearance: The drug (clindamycin phosphate) powder was examined for its organoleptic properties like colour, taste and odour. 
Solubility study: Solubility studies were performed in distilled water; $0.1 \mathrm{~N}$ hydrochloric acid, ethanol, methanol, Phosphate buffer $\mathrm{pH} 7.4$ at room temperature $\left(25 \pm 2^{0} \mathrm{C}\right)$. An excess amount of drug was added to $5 \mathrm{ml}$ of solvent in screw-capped glass vials; these were mechanically shaken for 48 hours at $25^{\circ} \mathrm{C}$ until equilibrium was achieved. Aliquots were withdrawn, filtered through a membrane filter $(0.45 \mu)$ and spectrophotometrically analyzed for solubility.

FTIR Spectra of clindamycin phosphate: IR spectra of physical mixture of drug and excipients were recorded by $\mathrm{KBr}$ method using Fourier Transform Infrared Spectrophotometer. A base line correction was made using dried potassium bromide pellet. The potassium bromide-drug pellet of approximately $1 \mathrm{~mm}$ diameter was prepared by grinding 3-5 $\mathrm{mg}$ of physical mixture of drug-excipients with $100-150 \mathrm{mg}$ of potassium bromide in pressure compression machine. The sample pellet was mounted in IR compartment and scanned at wavelengths $4000 \mathrm{~cm}^{-1}$ to $400 \mathrm{~cm}^{-1}$.

pH measurment: $\mathrm{pH}$ was determined by digital $\mathrm{pH}$ meter. In this method $1 \mathrm{gm}$ of clindamycin phosphate powder was accurately weighed and dissolved in $5 \mathrm{ml}$ of ethanol and diluted to $100 \mathrm{ml}$ with distilled water with sonication. The solution was filtered and $\mathrm{pH}$ of the filtrate was measured with digital $\mathrm{pH}$ meter.

Melting point determination: It is one of the parameters for the purity of drugs. Melting point was determined digital melting point apparatus (Chemline CL-725). The sample (2-4 mg) was heated in a fuse capillary tube at a rate of $5^{\circ} \mathrm{C} / \mathrm{min}$.

Determination of Wavelength Maxima: Accurately weighed $10 \mathrm{mg}$ of drug was dissolved in $100 \mathrm{ml}$ of phosphate buffer $\mathrm{pH} 7.4$ in a $100 \mathrm{ml}$ volumetric flask. $1 \mathrm{ml}$ of this stock solution was pipetted into a $10 \mathrm{ml}$ volumetric flask and volume made up to the mark with phosphate buffer $\mathrm{pH}$ 7.4. The resulting solution was scanned using UV/Vis double beam spectrophotometer.

\section{Preparation of calibration curve of clindamycin} phosphate

(a) Calibration curve in phosphate buffer pH 7.4: 10 $\mathrm{mg}$ of clindamycin phosphate was weighed accurately and dissolved in $5 \mathrm{ml}$ of methanol in a $100 \mathrm{ml}$ of volumetric flask and volume was made up to $100 \mathrm{ml}$ with the phosphate buffer $\mathrm{pH} 7.4$. Aliquot of $1 \mathrm{ml}$ of this solution was withdrawn and transferred to $10 \mathrm{ml}$ volumetric flask and diluted to $10 \mathrm{ml}$ with $\mathrm{pH} 7.4$ phosphate buffer to obtain a stock solution of $10 \mu \mathrm{g} / \mathrm{ml}$. From this stock solution, aliquots of $1 \mathrm{ml}, 2 \mathrm{ml} 3 \mathrm{ml} 4$ $\mathrm{ml}$...... $10 \mathrm{ml}$ were transferred to $10 \mathrm{ml}$ volumetric flasks and volume was made up to $10 \mathrm{ml}$ phosphate buffer $\mathrm{pH}$ 7.4. Take $2 \mathrm{ml}$ of this solution and add one $\mathrm{ml}$ methyl orange and extracted with $3 \mathrm{ml}$ chloroform pipette out the chloroform layer and the absorbance of these solutions was measured at $486 \mathrm{~nm}$ against a blank phosphate buffer $\mathrm{pH}$ 7.4. The calibration curve was obtained by plotting the absorbance of clindamycin phosphate versus the concentration of clindamycin phosphate. The straight line of best fit was obtained by using linear regression analysis program.

\section{Formulation and development}

Formulation development of Clindamycin phosphate loaded transfersomes ${ }^{10-18}$

Soya-phosphatidylcholine, Span 80 (95:05, 90:10, 85:15, $80: 20$, and 85:15) and Clindamycin phosphate (100mg) were dissolved alcohol. Then solution was put in a round bottom flask. These were then dissolved by shaking. Thin film was then formed by keeping it in the rotator vaccum evaporator at $40^{\circ} \mathrm{C}$. Final traces of solvent are removed under vacuum. The deposited lipid film is hydrated with the appropriate buffer by rotation at 60 rpm for 1 hour at room temperature. The resulting vesicles are swollen for 2 hours at room temperature. The multilamellar lipid vesicles (MLV) are then sonicated at room temperature. This thin film was then hydrated by phosphate buffer saline to get the transferosome.

Table 1: Formulation code and variable used in preparation of transferosome

\begin{tabular}{|c|c|c|c|}
\hline S.No. & Formulation code & $\begin{array}{c}\text { PC:S } \\
(\mathbf{m g})\end{array}$ & $\begin{array}{c}\text { Drug } \\
(\mathbf{m g})\end{array}$ \\
\hline 1 & TE1 & $95: 05$ & 100 \\
\hline 2 & TE2 & $90: 10$ & 100 \\
\hline 3 & TE3 & $85: 15$ & 100 \\
\hline 4 & TE4 & $80: 20$ & 100 \\
\hline 5 & TE5 & $80: 20$ & 100 \\
\hline 6 & TE6 & $85: 15$ & 100 \\
\hline \multicolumn{3}{|c|}{ SP=span 80, PC=phosphatidylcholine } \\
\hline
\end{tabular}

\section{Preparation of Gels}

Preparation of carbopol gel base: 0.5 g Carbopol 934 was weighed and dispersed in water with mild stirring and allowed to swell for 24 hours to obtain $0.5 \%$ gel. Later $2 \mathrm{ml}$ of glycerin was added to for gel consistency. Similarly 1 and $2 \%$ carbopol gels were prepared.

Table 2: Composition of different gel base

\begin{tabular}{|c|c|}
\hline Formulation & Carbopol (\%) \\
\hline TF1 & 0.5 \\
\hline TF2 & 1.0 \\
\hline TF3 & 2.0 \\
\hline
\end{tabular}

Preparation of transfersomes gels: $1 \mathrm{~g}$ of transfersomes formulation was dissolved in $10 \mathrm{ml}$ of ethanol and centrifuged at $6000 \mathrm{rpm}$ for 20 minutes to remove the unentrapped drug. The supernant was decanted and sediment was incorporated into the gel vehicle.

The incorporation of the transfersomes into gels was achieved by slow mechanical mixing at $25 \mathrm{rpm}$ for 10 minutes. The optimized formulation was incorporated into three different gel concentration $0.5,1$ and $2 \% \mathrm{w} / \mathrm{w}$. 


\section{Evaluation of clindamycin phosphate loaded transfersomes}

Microscopic observation of prepared
transfersomes

An optical microscope (cippon, Japan) with a camera attachment (Minolta) was used to observe the shape of the prepared transfersomes formulation.

Vesicle size determination ${ }^{12-13}$ : Vesicle size was determined using the particle size analyzer (Malvern Master Sizer, Malvern Instruments Ltd., Malvern, UK)

Entrapment efficiency ${ }^{14-15}$ : Entrapment efficiency was determined by measuring the concentration of unentrapped free drug in aqueous medium. About $1 \mathrm{ml}$ of the drug loaded transfersomes dispersion was placed in the Ependorf tubes and centrifuged at 10,000 rpm for $30 \mathrm{~min}$. The transfersomes along with encapsulated drug were separated at the bottom of the tubes. Plain transfersomes without Clindamycin phosphate was used as blank sample and centrifuged in the same manner. In order to measure the free drug concentration, the UV absorbance of the supernatant was determined at 486 nm.

\section{Evaluation of Gels}

Determination of $\mathbf{p H}^{\mathbf{1 6 , 1 7}}$ : Weighed $50 \mathrm{gm}$ of gel formulation were transferred in $10 \mathrm{ml}$ of beaker and measured it by using the digital $\mathrm{pH}$ meter. $\mathrm{pH}$ of the topical gel formulation should be between 3-9 to treat the skin infections.

Spreadability ${ }^{17,21}$ : A modified apparatus suggested was used for determining spreadability. The spreadability was measured on the basis of slip and drag characteristics of the gels. The modified apparatus was fabricated and consisted of two glass slides, the lower one was fixed to a wooden plate and the upper one was attached by a hook to a balance. The spreadability was determined by using the formula: $\mathrm{S}=\mathrm{ml} / \mathrm{t}$, where $\mathrm{S}$, is spread ability, $\mathrm{m}$ is weight in the pan tied to upper slide and $t$ is the time taken to travel a specific distance and 1 is the distance traveled. For the practical purpose the mass, length was kept constant and ' $t$ ' was determined. The measurement of spreadability of each formulation was in triplicate and the average values are presented.

Drug content ${ }^{17,18}: 1 \mathrm{gm}$. of the prepared gel was mixed with $100 \mathrm{ml}$. of ethyl alcohol. Aliquots of different concentrations were prepared by suitable dilutions after filtering the stock solution and the absorbance was measured at $486 \mathrm{~nm}$. Drug content was calculated by linear regression analysis of the calibration curve.

In-vitro diffusion study ${ }^{20,21}$ : An in-vitro drug release study was performed using modified Franz diffusion cell. Dialysis membrane (Hi Media, Molecular weight 5000 Daltons) was placed between receptor and donor compartments. Transferosomal gel of Clindamycin Phosphate was placed in the donor compartment and the receptor compartment was filled with phosphate buffer, $\mathrm{pH} 7.4(24 \mathrm{ml})$. The diffusion cells were maintained at $37 \pm 0.5^{\circ} \mathrm{C}$ with stirring at $50 \mathrm{rpm}$ throughout the experiment. At different time interval, $5 \mathrm{ml}$ of aliquots were withdrawn from receiver compartment through side tube and analyzed for drug content by UV Visible spectrophotometer.

Stability studies $^{\text {20-21 }}$ : Optimized formulations of transfersomes gel were subjected to accelerated stability testing under storage condition at $4 \pm 1{ }^{\circ} \mathrm{C}$ and at room temperature $\left(28 \pm 1^{\circ} \mathrm{C}\right)$. Both formulations were stored in screw capped, amber colored small glass bottles at $4 \pm$ $1^{\circ} \mathrm{C}$ and $28 \pm 1{ }^{\circ} \mathrm{C}$. Analysis of the samples were characterized for vesicle size and drug content after a period of 7, 14, 21 and 28 days.

(a) Effect of storage temperature on vesicle size: Subsequent change in vesicle size of the formulations stored at $4 \pm 1^{\circ} \mathrm{C}$ and $28 \pm 1^{\circ} \mathrm{C}$ was determined using a Zetasizer (Malvern Instrument, UK) after a period of 7 , 14, 21 and 28 days.

(b) Effect of storage temperature on drug content: After storage for a specified period of time of 7, 14, 21 and 28 days, the drug content of both the formulations was determined. Drug content in transfersomes gel was determined spectrophotometrically to indirectly estimate the amount of drug entrapped in gel.

\section{RESULTS AND DISCUSSION}

\section{Physiochemical Properties of Clindamycin phosphate}

\section{Physical evaluation}

It refers to the evaluation by sensory characters-taste, appearance, odor, feel of the drug, etc.

Table 3: List of Sensory characters

\begin{tabular}{|c|c|c|}
\hline S. No. & Sensory characters & Result \\
\hline 1. & Colour & $\begin{array}{c}\text { White to off white } \\
\text { powder }\end{array}$ \\
\hline 2. & Odor & Odorless \\
\hline 3. & Taste & Tasteless \\
\hline
\end{tabular}

Solubility: Solubility of the drug was determined by taking some quantity of drug (about 1-2 mg) in the test tube separately and added the $5 \mathrm{ml}$ of the solvent (water, ethanol, methanol, 0.1N HCL, and $7.4 \mathrm{pH}$ buffer) Shake vigorously and kept for some time. Note the solubility of the drug in various solvents (at room temperature). 
Table 4: Solubility of Clindamycin phosphate

\begin{tabular}{|c|c|c|}
\hline Solvent used & Solubility & I.P. Ranges \\
\hline Distilled Water & Slightly soluble & 100 to1000 \\
\hline 0.1 N Hydrochloric acid & Slightly soluble & 100 to1000 \\
\hline Ethanol & Freely soluble & 1 to 10 \\
\hline Methanol & Freely soluble & 1 to 10 \\
\hline Phosphate buffer $\mathrm{pH} 7.4$ & Soluble & 10 to 30 \\
\hline
\end{tabular}

\section{Identification Test}

Sample of pure Clindamycin

The IR spectrum of sample drug shows the peak values which are characteristics of the drug and the graph were shown in figure no. 7.1

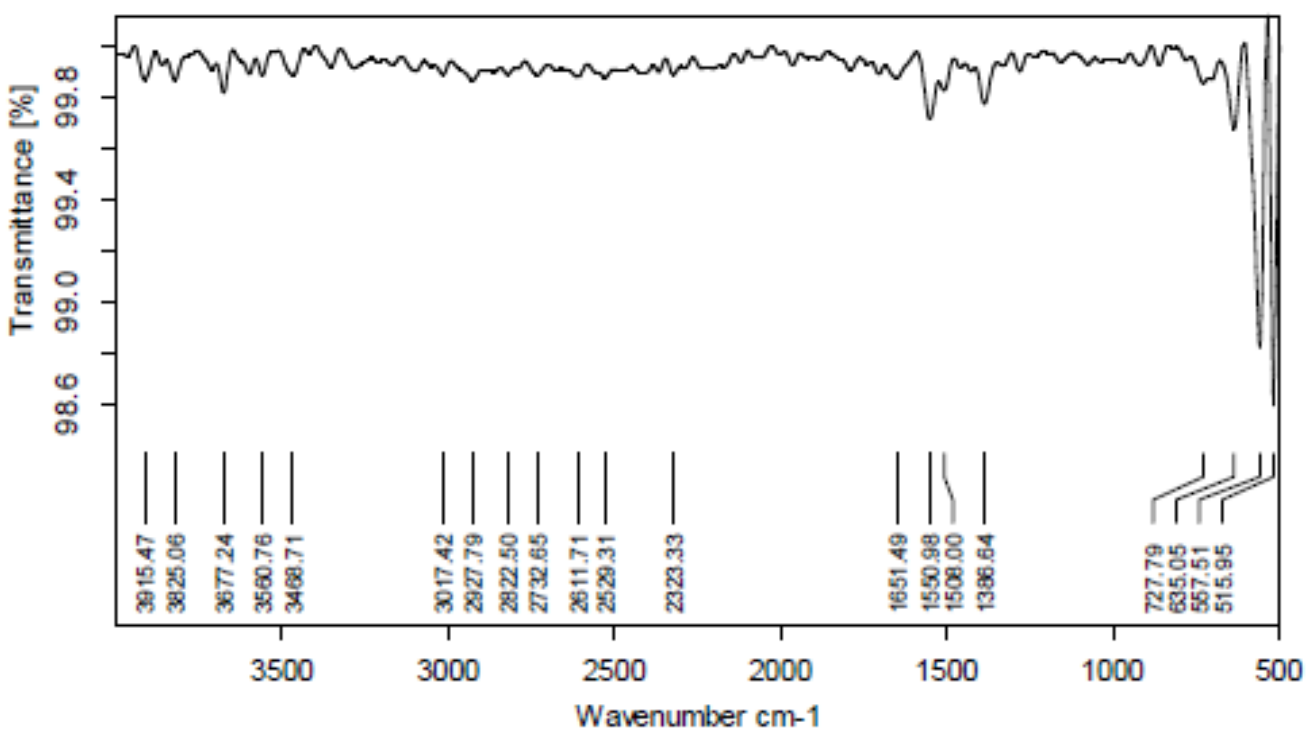

Figure 1: FT-IR spectrum of pure drug (Clindamycin phosphate)

Table 5: Interpretation of Clindamycin phosphate

\begin{tabular}{|c|c|c|}
\hline Sr. No. & Wave Number of drug $\left.\mathbf{( c m}^{-\mathbf{1}}\right)$ & Interpretation \\
\hline 1. & 1651.49 & C=O Stretching \\
\hline 2. & 1386.64 & C-N Stretching \\
\hline 3. & 2927.79 & C-H \\
\hline 4. & 3468.71 & O-H \\
\hline
\end{tabular}

Melting point:

Table 6: Melting point of the Clindamycin phosphate

\begin{tabular}{|c|c|c|}
\hline S. No. & Melting Point of Clindamycin phosphate & Average Melting Point of Clindamycin phosphate \\
\hline 1. & $140-142^{\circ} \mathrm{C}$ & $140-142^{\circ} \mathrm{C}$ \\
2. & $141-142^{\circ} \mathrm{C}$ & \\
3. & $140-142^{\circ} \mathrm{C}$ & \\
\hline
\end{tabular}

\section{Determination of $\lambda_{\text {max }}$ of Clindamycin phosphate:}

The $\lambda_{\max }$ of Clindamycin phosphate was determined by running the spectrum of drug solution in double beam ultraviolet spectrophotometer. 


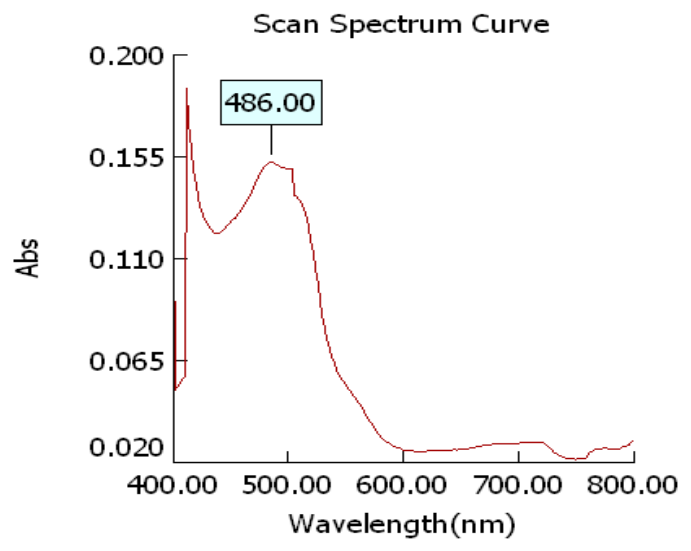

Figure 2: Wavelength maxima of Clindamycin phosphate buffer pH 7.4

Calibration curve of Clindamycin phosphate at $\lambda_{\text {max }}$ 486nm

Table 7: Calibration curve of Clindamycin phosphate

\begin{tabular}{|c|c|c|}
\hline S. No. & Conc. $(\boldsymbol{\mu g} / \mathbf{m l})$ & Absorbance \\
\hline 1 & 10 & 0.109 \\
\hline 2 & 20 & 0.247 \\
\hline 3 & 30 & 0.389 \\
\hline 4 & 40 & 0.519 \\
\hline 5 & 50 & 0.664 \\
\hline
\end{tabular}

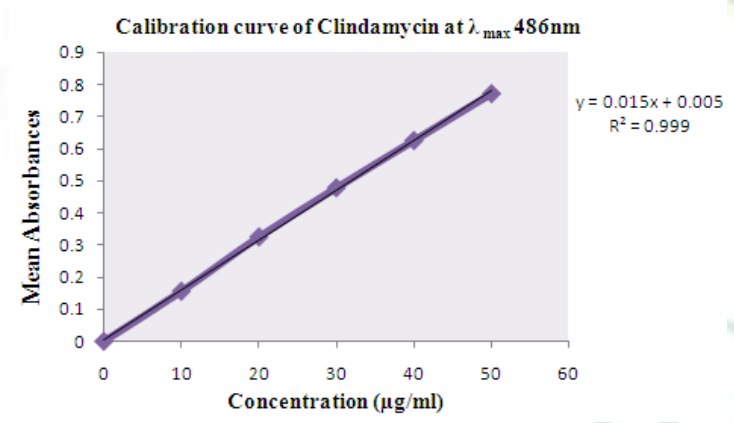

Figure 3: Calibration curve of Clindamycinin phosphate buffer pH 7.4 at $486 \mathrm{~nm}$

The linear regression analysis was done on Absorbance data points. The results are as follow for standard curve

Slope $=0.015$

The intercept $=0.005$

The correlation coefficient $\left(r^{2}\right)=0.999$

\section{Compatibility studies of drug and excipients}

In the compatibility testing program, blends of drug and excipients are prepared by triturating the drug with Individual excipients.

Procedure: Taken $50 \mathrm{mg}$ accurately weigh of clindamycin phosphate dry powder and $50 \mathrm{mg}$ of excipients and mix the blend of drug and excipients and binary/tertiary blends of extract and excipients were prepared and transferred to inert glass vials. The mouths of the vials were covered with rubber closures followed by the aluminum seal caps. Binary/tertiary blends of extract and excipients, clindamycin neat and excipients were stored at $4^{\circ} \mathrm{C}$ (refrigerator) as control and at $40^{\circ} \mathrm{C} / 75 \% \mathrm{RH}$ for accelerated stability studies for 4 weeks. The $\lambda \max$ were recorded for determination of Compatibility of clindamycin phosphate with other excipients.

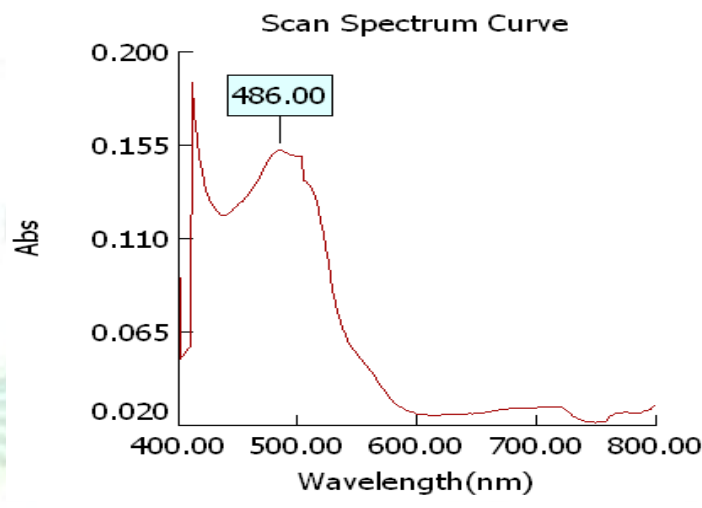

Figure 4: Wavelength maxima of Clindamycin phosphate

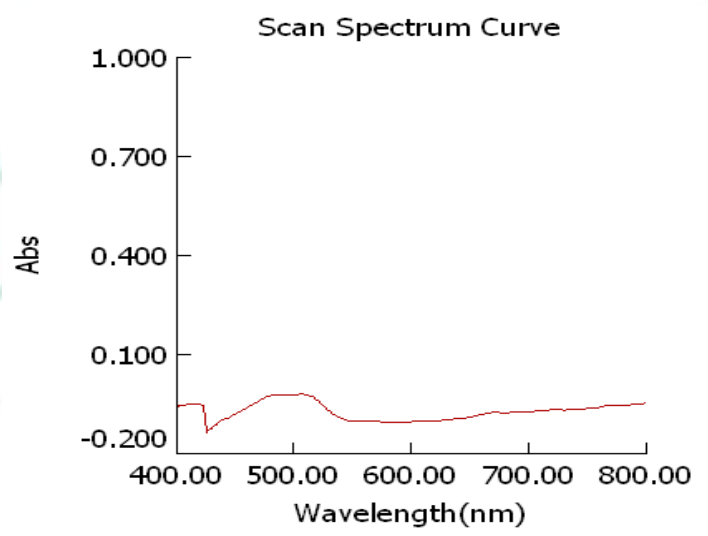

Figure 5: Wavelength maxima of Clindamycin phosphate + Excipients

Table: Comparative data of preformulation studies of clindamycin phosphate

\begin{tabular}{|l|l|}
\hline Parameter & Observation \\
\hline Melting Point & $140-142^{\circ} \mathrm{C}$ \\
\hline pH (1\% w/v solution) & 7.8 \\
\hline Hausner ratio & 1.28 \\
\hline Solubility & $\begin{array}{l}\text { Freely soluble in Ethanol, Methanol. Soluble in Phosphate Buffer 7.4, slightly } \\
\text { soluble in water and 0.1 N HCL. }\end{array}$ \\
\hline Loss on Drying (\%) & 0.72 \\
\hline
\end{tabular}


The preliminary study showed that clindamycin phosphate is white, crystalline, odorless powder. It is freely soluble in Ethanol, Methanol. Soluble in Phosphate Buffer 7.4, slightly soluble in water and $0.1 \mathrm{~N}$ HCL. The melting point was in the range of $140-142^{\circ} \mathrm{C}$ which is in compliance with the standard value of 140 $142^{\circ} \mathrm{C}$.

From the FTIR data of the physical mixture it is clear that functionalities of drug have remained unchanged including intensities of the peak. This suggests that during the process drug and cholesterol has not reacted with the drug to give rise to reactant products. So there is no interaction between them which is in favor to proceed for formulation of vesicular drug delivery system. The U.V study shows that the drug and Excipient are compatible with each other.

\section{Results of Evaluation of transfersomes}

\section{Microscopic observation of prepared transfersomes}

An optical microscope (cippon, Japan) with a camera attachment (Minolta) was used to observe the shape of the prepared transfersomes formulation.

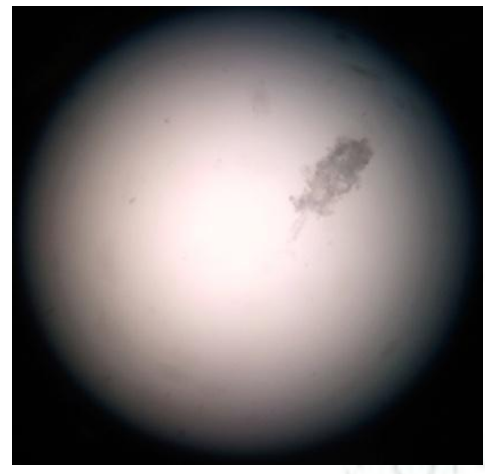

T1

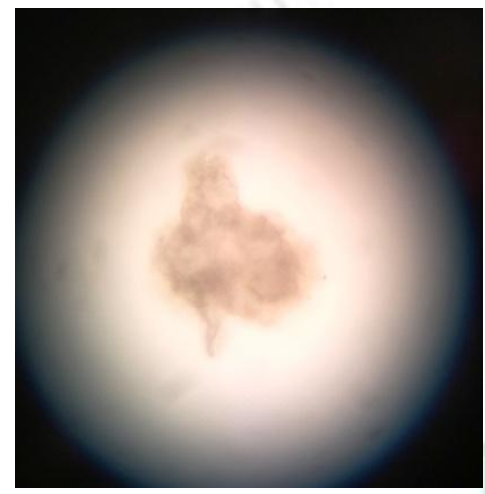

T4

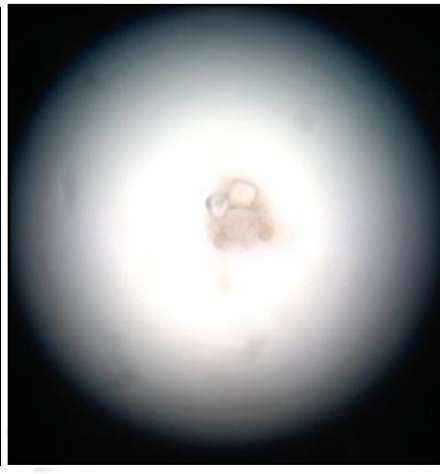

T2

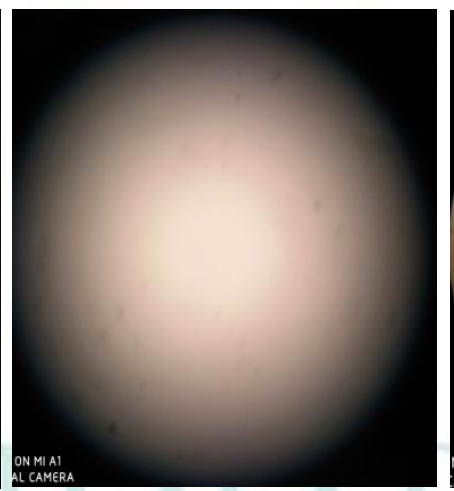

T5

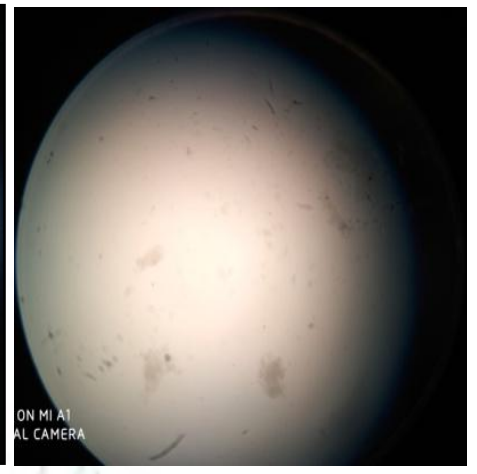

T3

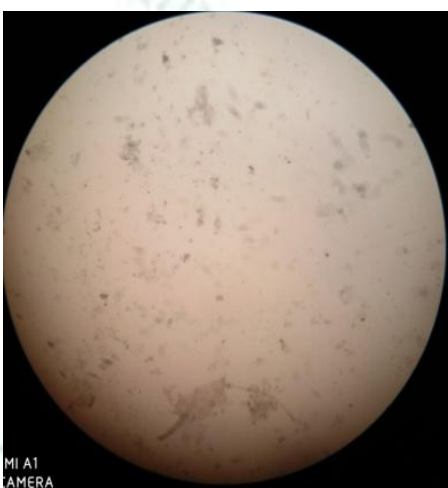

T6

Figure 6: Microscopic observation of transfersomes formulations

\section{Evaluation of Vesicle size and Entrapment efficiency}

Table includes the value of vesicle size, and entrapment efficiency. The vesicle size of all transfersomes varied between 178.89 and $245.65 \mathrm{~nm}$ where as entrapment efficiency was found between 61.15 to $75.65 \%$.

Table: 9: Evaluations of transfersomes for Vesicle size and Entrapment efficiency

\begin{tabular}{|c|c|c|}
\hline Formulation & Vesicle Size (nm) & Entrapment efficiency (\%) \\
\hline T1 & $198.89 \pm 0.85$ & $70.56 \pm 1.25$ \\
\hline T2 & $\mathbf{1 7 8 . 5 0} \pm \mathbf{0 . 2 1}$ & $\mathbf{7 5 . 6 5} \pm \mathbf{1 . 9 8}$ \\
\hline T3 & $210.56 \pm 1.24$ & $69.98 \pm 1.65$ \\
\hline T4 & $225.65 \pm 0.98$ & $61.15 \pm 1.23$ \\
\hline T5 & $241.32 \pm 0.65$ & $65.65 \pm 1.45$ \\
\hline T6 & $245.65 \pm 0.78$ & $68.98 \pm 1.32$ \\
\hline
\end{tabular}

Results showed that in formulation $\mathrm{T} 2$ which contain smallest vesicle size and increase in entrapment efficiency, Formulation T2 Sleeted as optimized formulation for further evaluation. 


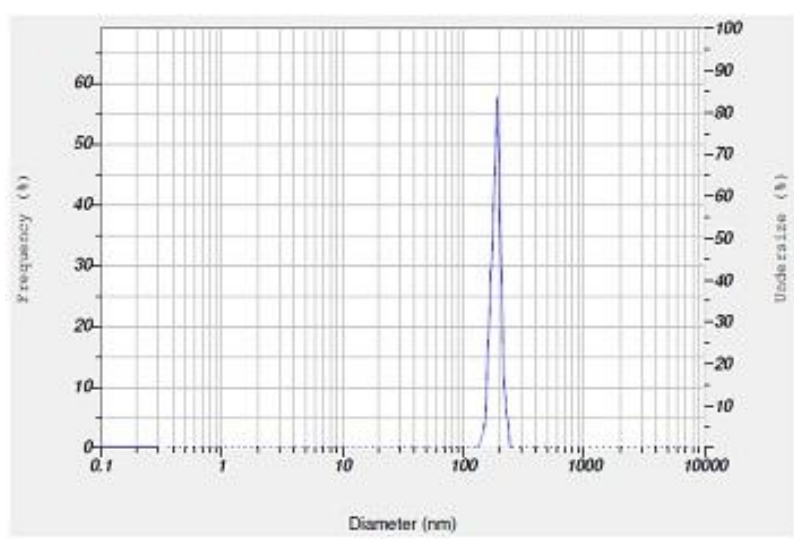

Figure 7: Vesicle Size of Optimized transfersomes formulation $\mathrm{T} 2$

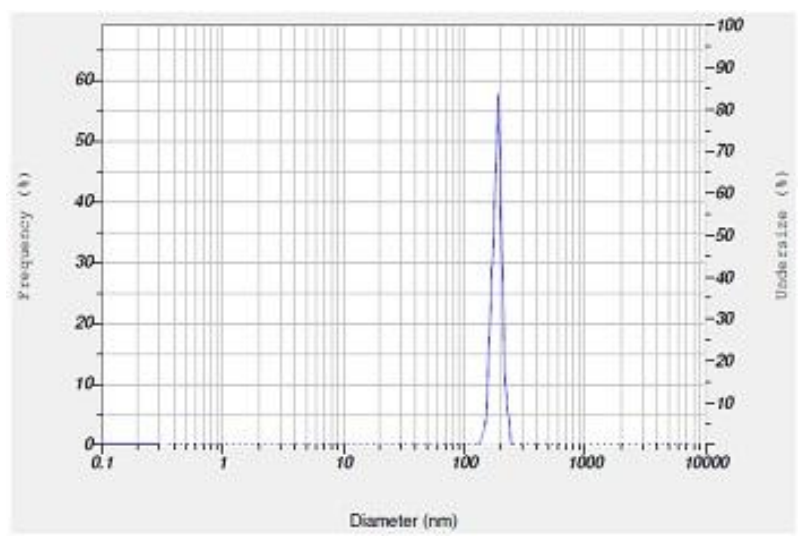

Figure 8: Zeta potential of Optimized transfersomes formulation $\mathbf{T} 2$

Table 10: Vesicle size and entrapment efficiency of optimized formulation

\begin{tabular}{|c|c|c|c|}
\hline Formulation Code & Vesicle Size (nm) & $\begin{array}{c}\text { Entrapment } \\
\text { Efficiency }(\boldsymbol{\%})\end{array}$ & $\begin{array}{c}\text { Zeta potential } \\
(\mathbf{m V})\end{array}$ \\
\hline T2 & 178.5 & $73.70 \pm 0.995$ & -48.5 \\
\hline
\end{tabular}

\section{Evaluation of Transfersomes Gel}

Drug content: Drug content is most important in transfersomes formulation and the data found are satisfactory. It was found to be 95.65 to $97.98 \%$ which shows the good capacity of formulation to hold the drug. The maximum drug content was found in formulation TG-2 $(97.98 \%)$

pH: In transdermal drug delivery system $\mathrm{pH}$ plays an important role, the result of transfersomes formulation shows that all the formulations are suitable for skin delivery. The $\mathrm{pH}$ value of the prepared transfersomes gels was found to be in limits of 6.87-6.99. The $\mathrm{pH}$ of optimized formulation TG-2 was found to be 6.99 .

Spreadibility: A modified apparatus was used for determining spreadability. The spreadability was measured on the basis of slip and drag characteristics of the gels and was in the range of $11.65-13.25 \mathrm{gms} . \mathrm{cm}$. /sec. The gels should have optimum spreadability because very high and very low spreadability values indicate that the application of the gel to the site is difficult. The spreadability of optimized formulation TG-2 was found to be 12.65 .

Viscosity measurements: The viscosity of gels was determined by using a Brookfield viscometer DV-II model. T-Bar spindle in combination with a helipath stand was used to measure the viscosity and have accurate readings.

Five readings taken over a period of 60 seconds were averaged to obtain viscosity. The Viscosity of optimized formulation was found to be $2369 \mathrm{cps}$.

Table 11: Results of transfersomes gel formulations

\begin{tabular}{|c|c|c|c|c|}
\hline Code & $\begin{array}{c}\text { Drug content } \\
(\%)\end{array}$ & pH & $\begin{array}{c}\text { Spreadability } \\
(\text { Gm.cm/sec. })\end{array}$ & $\begin{array}{c}\text { Viscosity } \\
(\mathbf{c p s})\end{array}$ \\
\hline TG1 & $95.65 \pm 0.12$ & $6.98 \pm 0.12$ & $13.25 \pm 1.25$ & $2658 \pm 15$ \\
\hline TG 2 & $97.98 \pm 0.15$ & $6.99 \pm 0.15$ & $12.65 \pm 1.23$ & $2154 \pm 25$ \\
\hline TG 3 & $96.56 \pm 0.25$ & $6.87 \pm 0.08$ & $11.65 \pm 1.56$ & \\
\hline
\end{tabular}

In-vitro drug release study: In-vitro diffusion study of the transfersomes gel (TG1, TG2, and TG3) was performed using modified Franz diffusion cell with dialysis membrane in phosphate buffer $\mathrm{pH} 7.4$ for a period of 10 hours. The data obtained from diffusion studies are summarized in Table. The release rate of drug from transfersomes formulation over dialysis membrane was significantly higher than its transport across skin, indicating the barrier properties of skin for drugs. The in vitro release data were fitted into different kinetic models viz Zero-order, First order, Higuchi model and Korsmeyer Peppas equation. Zero-order 
plots, First order plots, Higuchi plots and Korsmeyer Peppas plots are shown in Figure. The zero-order plots were found to be fairly linear. In order to determine the exact mechanism of drug release from salicylic acid gel the in vitro release data were fitted to Korsmeyer Peppas equation and the ' $n$ ' values were calculated. ' $n$ ' values were found to be in the range of $0.5<\mathrm{n}<1.0$, which suggests that the drug release mechanism from the gel followed non-Fickian diffusion mechanism (Anamolous transport). Transfersomes gel released drug in controlled release manner in 8 hour but in case of marketed formulation there is no controlled release of drug from gel. The release of the drug from transfersomes gel was found to follow the order:

\section{TG2> TG3> TG1}

\section{In-vitro drug release data of transfersomes gel formulation}

Table 12: In-vitro drug release data for TG2

\begin{tabular}{|c|c|c|c|c|c|c|}
\hline $\begin{array}{c}\text { Time } \\
\text { (h) }\end{array}$ & $\begin{array}{c}\text { Square Root } \\
\text { of Time(h) }\end{array}$ & $\begin{array}{c}\mathbf{1 / 2} \\
\text { Time }\end{array}$ & $\begin{array}{c}\text { Cumulative* \% } \\
\text { Drug Release }\end{array}$ & $\begin{array}{c}\text { Log } \\
\text { Cumulative \% } \\
\text { Drug Release }\end{array}$ & $\begin{array}{c}\text { Cumulative \% } \\
\text { Drug } \\
\text { Remaining }\end{array}$ & $\begin{array}{c}\text { Log Cumulative } \\
\text { \% Drug } \\
\text { Remaining }\end{array}$ \\
\hline 0.5 & 0.70711 & -0.301 & 20.25 & 1.306 & 79.75 & 1.902 \\
\hline 1 & 1 & 0.000 & 40.56 & 1.608 & 59.44 & 1.774 \\
\hline 2 & 1.41421 & 0.301 & 48.98 & 1.690 & 51.02 & 1.708 \\
\hline 4 & 2 & 0.602 & 69.98 & 1.845 & 30.02 & 1.477 \\
\hline 6 & 2.44949 & 0.778 & 75.65 & 1.879 & 24.35 & 1.386 \\
\hline 8 & 2.82843 & 0.903 & 89.98 & 1.954 & 10.02 & 1.001 \\
\hline 10 & 3.16228 & 1 & 95.56 & 1.980 & 4.44 & 0.647 \\
\hline
\end{tabular}

*Average of three reading

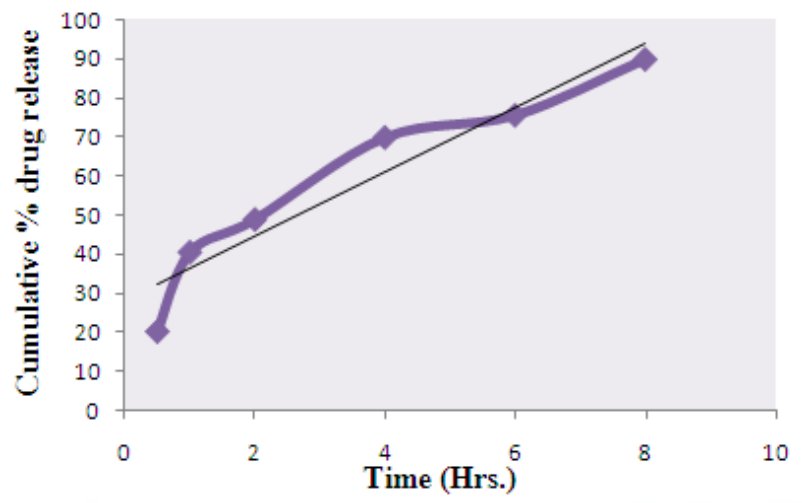

Figure 9: Cumulative \% drug released Vs Time

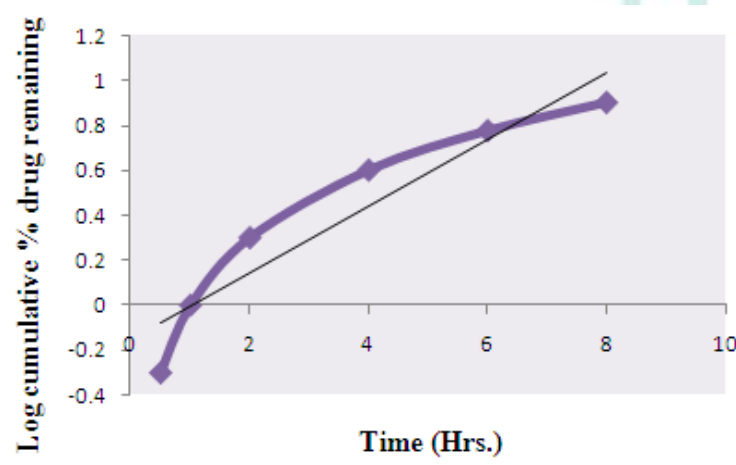

Figure 10: Log cumulative \% drug remaining Vs Time

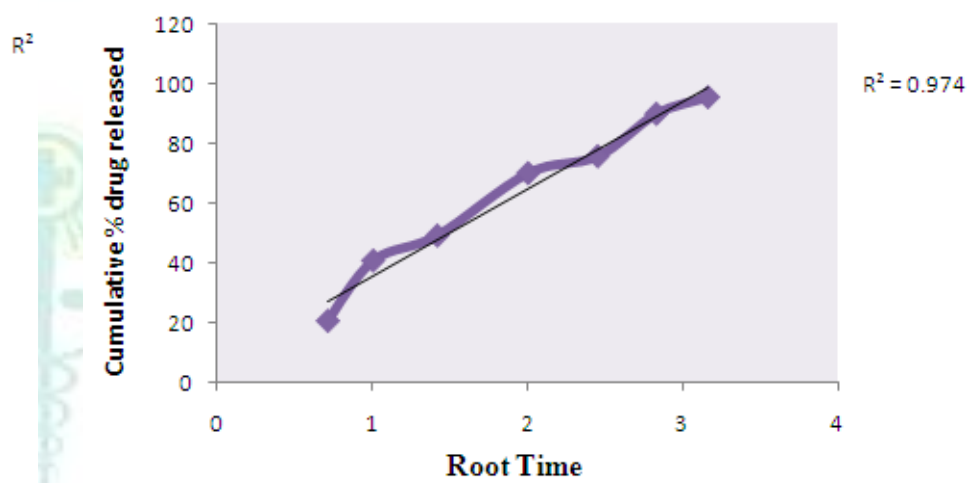

Figure 11: Cumulative \% drug released Vs Square root of Time

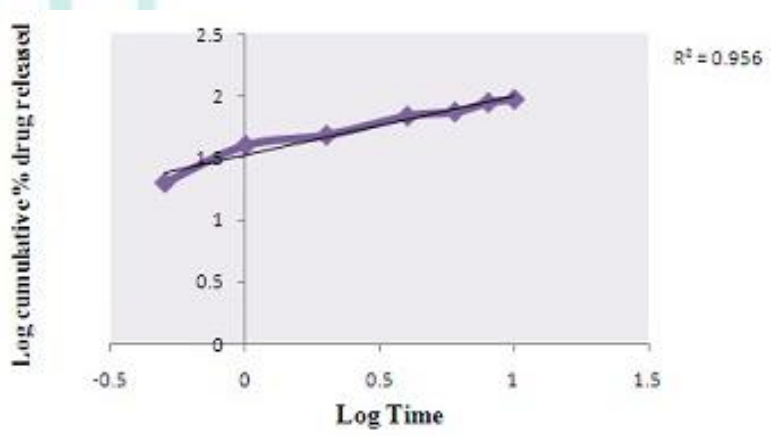

Figure 12: Log cumulative \% drug released Vs log Time

Table 13: Regression analysis data of transfersomes gel formulation

\begin{tabular}{|c|c|c|c|c|}
\hline \multirow{3}{*}{ Batch } & Zero Order & First Order & Higuchi's Model & $\begin{array}{c}\text { Korsmeyers Peppas } \\
\text { Equation }\end{array}$ \\
\cline { 2 - 5 } & $\mathbf{R}^{\mathbf{2}}$ & $\mathbf{R}^{\mathbf{2}}$ & $\mathbf{R}^{\mathbf{2}}$ & $\mathbf{R}^{\mathbf{2}}$ \\
\hline TG2 & 0.941 & 0.891 & 0.974 & 0.956 \\
\hline
\end{tabular}


Stability studies: Stability studies for optimized formulations were carried out at $4.0 \pm 0.5^{\circ} \mathrm{C}$ and $28 \pm$ $0.5^{\circ} \mathrm{C}$ for a period of four weeks. There was no significant variation found in physical appearance, average particle size and \% drug content of the transfersomes gel.

\section{SUMMARY AND CONCLUSION}

The preliminary study showed that clindamycin is white, crystalline, odorless powder. It is freely soluble in Ethanol, Methanol. Soluble in Phosphate Buffer 7.4, slightly soluble in water and $0.1 \mathrm{~N} \mathrm{HCL}$. The melting point was in the range of $140-142^{\circ} \mathrm{C}$ which is in compliance with the standard value of $140-142^{\circ} \mathrm{C}$.

From the FTIR data of the physical mixture it is clear that functionalities of drug have remained unchanged including intensities of the peak. This suggests that during the process drug and cholesterol has not reacted with the drug to give rise to reactant products. So there is no interaction between them which is in favor to proceed for formulation of vesicular drug delivery system. The U.V study shows that the drug and Excipient are compatible with each other.

Total Six formulations were prepared using varying amount of Soya-phosphatidylcholine, Span 80 and drug and evaluated for Vesicle size and Entrapment efficiency. Formulation T2 which contain smallest vesicle size and increase in entrapment efficiency, Formulation T2 Sleeted as optimized formulation for further evaluation.

The optimized batch of Transfersomes was further incorporated into gel base and evaluated for $\mathrm{pH}$, Spreadability, Measurement of viscosity, Drug content and In-vitro diffusion study.

Drug content is most important in transfersomes formulation and the data found are satisfactory. It was found to be 95.65 to $97.98 \%$ which shows the good capacity of formulation to hold the drug. The maximum drug content was found in formulation TG-2 (97.98\%)

\section{REFERENCES}

1. Prajapati S. T, Patel C.G and Patel C.N, " Transferosome: A vesicular carrier system for Transdermal drug delivery." Asian journal of Biochemical and Pharmaceutical Research, 2011; 1:507-524

2. Cunliffe WJ. The sebaceous gland and acne-40 years on Dermatology. 1998; 196:9-15.

3. Leyden JJ. Therapy for acne vulgaris. N Engl J Med. 1997; 336:1156-1162.

4. Gollnick H, Schramm M. Topical drug treatment in acne. Dermatology. 1998; 196:119-125.

5. Swathi, Sowjanya et al, Various aspects of Pharmaceutical Preformulation: A Review, PHARMANEST: An International Journal of Advances in Pharmaceutical Sciences. 2013; 4(2):171-190.

6. Bharate SS, Bharate SB, Bajaj AN, "Interactions and incompatibilities of pharmaceutical excipients with active pharmaceutical ingredients: a comprehensive review," Journal of Excipients and Food Chemicals, 2010; 1(3):3-26.

7. Lachman L, Liebermann HA, Kanig JL, The Theory and Practice of Industrial Pharmacy, Stipes Publishing, 3rd edition, 1986
In transdermal drug delivery system $\mathrm{pH}$ plays an important role, the result of transfersomes formulation shows that all the formulations are suitable for skin delivery. The $\mathrm{pH}$ value of the prepared transfersomes gels was found to be in limits of 6.87-6.99. The $\mathrm{pH}$ of optimized formulation TG-2 was found to be 6.99 .

A modified apparatus was used for determining spreadability. The spreadability was measured on the basis of slip and drag characteristics of the gels and was in the range of $11.65-13.25 \mathrm{gms}$. $\mathrm{cm}$. / $/ \mathrm{sec}$. The gels should have optimum spreadability because very high and very low spreadability values indicate that the application of the gel to the site is difficult. The spreadability of optimized formulation TG-2 was found to be 12.65

The best method for the selection of spindle was trial and error starting from T91 spindle. Spindles in increasing number were used depending on the $\%$ torque and error. The goal is to obtain a viscometer dial or display (\% torque) reading between $10 \& 100$, the relative error of measurement improves as the reading approaches 100. Spindle T 95 was found to be suitable and was used for the measurement of viscosity of all the gels. The Helipath T- Bar spindles were rotated up and down in the sample giving variable viscosities at a number of points programmed over the time. Five readings taken over a period of 60 seconds were averaged to obtain viscosity. The Viscosity of optimized formulation was found to be $2369 \mathrm{cps}$.

Stability studies for optimized formulations were carried out at $4.0 \pm 0.5^{\circ} \mathrm{C}$ and $28 \pm 0.5^{\circ} \mathrm{C}$ for a period of four weeks. There was no significant variation found in physical appearance, average particle size and \% drug content of the transfersomes gel.

From this study, it was concluded that the optimized batch of clindamycin, with high EE\% and small particle size. Also, the preparation of clindamycin as transfersomal gel has the ability to overcome the barrier properties of the skin and increase the drug release.

8. Aulton ME, Pharmaceutics: The Science of Dosage Form Design, Churchill Livingstone, London, UK, 2006.

9. Martin EW, Remington's the Science and Practice of Pharmacy, Lippincott Williams \& Wilkins, 21st edition, 2005.

10. Soni P, Saini T. Non-Ionic surfactant vesicles (niosomes) based novel ophthalmic formulation of timolol maleate. Journal of Drug Delivery and Therapeutics, 2017; 7(7):59-61. https://doi.org/10.22270/jddt.v7i7.1587

11. Jain S, Jain P, Maheshwari UR, Jain N. Transfersomes A novel vesicular carrier for enhanced transdermal delivery: Development, characterization, and performance evaluation. Drug Dev Ind Pharm 2003; 29:1013-26

12. Duangjit $S$, Opanasopit $P$, Rojanarata $T$, Ngawhirunpat $T$. Evaluation of meloxicam-loaded cationic transfersomes as transdermal drug delivery carriers. AAPS PharmSciTech 2013; $14: 133-40$

13. Jaiswal P, Kesharwani S, Kesharwani R, Patel D, Ethosome: A new technology used as topical \& transdermal delivery system. Journal of Drug Delivery and Therapeutics, 2016; 6(3):7-17. https://doi.org/10.22270/jddt.v6i3.1245 
14. Shingade G. Review on: Recent trend on transdermal drug delivery system. Journal of Drug Delivery and Therapeutics, 2012; 2(1):66-75. https://doi.org/10.22270/jddt.v2i1.74

15. Modi CD and Bharadia PD, "Transfersomes: New Dominants for Transdermal Drug Delivery", American Journal of Pharmtech Research, 2012; 2(3):71-91.

16. Farooqui N, Kar M, Jain S. Development and evaluation of proniosomes as drug carriers for transdermal delivery of ketorolac tromethamine. Journal of Drug Delivery and Therapeutics, 2017; 7(7):38-40. https://doi.org/10.22270/jddt.v7i7.1580

17. Nimker V, Jamal H, Ghosh P, Jain S, Beotra A. Liposomes: drug delivery system or possible doping agent?. Journal of Drug Delivery and Therapeutics, 2017; 7(1):25-29. https://doi.org/10.22270/jddt.v7i1.1369
18. Cevc G, Blume G, Scha“tzlein A., Transferosomes-mediated transepidermal delivery improves the regiospecificity and biological activity of corticosteroids in vivo. J Control Rel., 1997, 45, 211-26.

19. Hanpramukkun N., Kongmuang S., Chansiri G., The stability of clindamycin phosphate in w/o/w multiple emulsions, Int $\mathrm{J}$ Pharm Sci Tec, 2009, 3(2), 1-7.

20. Jivrani Shilpa D, Patel Vijay K, Formulation, Development And Evaluation of Niosomal Drug Delivery System For Clindamycin Phosphate, Pharma Science Monitor, 2014, 5(2), 256-274.

21. Mishra M. and Biswal P., Complexation, Optimization, Formulation development and characterization of clindamycin phosphate gel using zinc acetate dehydrate, international jouranal of pharmacy, 2012; 2(3):472-486. 